\title{
IMPLEMENTASI KARTU BER-PASSWORD BERBASIS MIKROKONTROLER AT89S51 UNTUK SISTEM KONTROL KEHADIRAN
}

\author{
Elma Yusnita ${ }^{1}$, Wildian ${ }^{2}$, Harmadi $^{2}$ \\ ${ }^{1}$ Program Pascasarjana FMIPA UniversitasAndalas \\ ${ }^{2}$ Jurusan Fisika, FMIPA UniversitasAndalas, 25163 \\ Email: ${ }^{1}$ elma.yusnita@yahoo.com;
}

\begin{abstract}
ABSTRAK
Telah dirancang suatu sistem kontrol kehadiran berbasis mikrokontroler AT89S51 untuk menginformasikan kehadiran dengan menggunakan kartu ber-paswword. Password dibuat dalam deretan 8 logika biner yang dipresentasikan oleh kombinasi bagian kartu yang berlubang dan tak-berlubang. Lubang-lubang digunakan untuk melewatkan cahaya dari 8 buah LED ke 8 buah fotodioda (jarak antara LED dan fotodioda adalah 0,5 cm) yang kemudian dibaca oleh mikrokontroler sebagai logika " 1 " $(4,8 \mathrm{~V})$. Berdasarkan data 8-bit yang diterimanya, mikrokontroler kemudian memerintahkan relay untuk menyalakan ataumematikan lampu nama yang sesuai dengan password yang dimasukkan ke kotak detektor. Pada kartu terdapat dua password, yaitu password untuk masuk (hadir) dan password untuk keluar (pulang). Sistem detektor dijalankan berdasarkan program yang ditulis menggunakan bahasa pemrograman BASCOM. Hasil uji keseluruhan terhadap kinerja alat memperlihatkan bahwa alat dapat membedakan password untuk masuk atau keluar, dan membedakan pemilik password untuk masuk atau keluar, dan membedakan pemilik password yang satu dengan yang lain.
\end{abstract}

Kata kunci : Mikrokontroler AT89S51, kartu ber-password, kehadiran.

\begin{abstract}
A control system based on microcontroller AT89S51 has been designed to inform the attendance using password cards. Passwords created in a row of 8 binary digits represented by a combination of holed and non-holed parts of the cards. These holes are used to channel light from 8 LEDs into 8 photodiodes (LED and photodiode are apart of $0,5 \mathrm{~cm}$ ). The data is then read by the microcontroller as a combination of logics " 1 " (4,8 V) and " 0 " (low). Accoarding to the 8 -bit data it received, microkontroller then ordered the relay to turn on or turn off the lights corresponding to the name of the password entered into the detector box. On the card there are two passwords, the password to get in (present) and password to exit. The detector system is run by a program written using a progamming language BASCOM. Overal test results show that the performance of the detector system can distinguish the password to get in or out, and distinguish one owner password from another.
\end{abstract}

Keywords: Microcontroller 89S51, password card, attendance.

\section{PENDAHULUAN}

Perkembangan ilmu pengetahuan dan teknologi, khususnya di bidang elektronika dan instrumentasi, memungkinkan dibuatnya berbagai sistem elektronik yang dapat memudahkan manusia dalam melakukan pekerjaan. Salah satu contoh dirancang dan direalisasikan prototype suatu sistem elektronik yang dapat memberikan informasi tentang kehadiran secara lebih praktis, efisien dan informatif dengan menggunakan kode password kartu berlubang berbasis mikrokontroler AT89S51. Penelitian tentang 
pemanfaatan kartu berlubang sebagai media password telah dilakukan antara lain oleh Riki (2007), Bhaskara (2009) dan Silitonga (2010).

Penelitian dilakukan menggunakan kartu berlubang sebagai media password dengan implementasi yang berbeda, seperti untuk mengidentifikasi kehadiran guru di sekolah. Variasi lubang yang berbeda akan memberikan kode password (dalam bentuk biner) berbeda untuk masing-masing orang. Detektor terdiri dari 8 pasang LED-fotodioda digunakan untuk mendeteksi kartu password seseorang ketika kartu tersebut dimasukkan ke kotak detektor. Rangkaian sistem detektor terdiri dari sensor merupakan tranduser masukan (piranti yang mengonversi energi dari bentuk yang satu ke bentuk yang lain) yang berfungsi menerima suatu bentuk energi (biasanya merupakan besaran fisis) dan mengonversinya menjadi sinyal elektris (Fraden, 1996).

Sensor cahaya digunakan untuk mengubah besaran cahaya menjadi besaran listrik. Prinsip kerja dari alat ini adalah mengubah energi dari foton menjadi elektron. Idealnya satu foton dapat membangkitkan satu elektron. Sistem detektor dibangun terdiri dari delapan pasang rangkaian elektronik yang masing-masing terdiri dari LED dan fotodiod. Fungsinya adalah untuk mendeteksi password yang dikodekan pada kartu berlubang.

Catudaya DC digunakan sebagai catu energi untuk seluruh sistem alat ukur ini. Sistem catudaya tersusun dari trafo step-downuntuk menurunkan tegangan, dua buah dioda sebagai penyearah, kapasitor sebagai penapis, dan IC regulator sebagai pengatur tegangan keluaran catudaya. Catudaya adalah suatu sistem filter penyearah yang mengubah tegangan AC menjadi tegangan DC. Catudaya menjadi bagian penting dalam elektronika yang berfungsi sebagai sumber tenaga listrik misalnya pada batry atau accu. Catudaya juga dapat digunakan sebagai perangkat yang memasok energi listrik untuk satu atau lebih beban listrik (Fadli, 2012).

Mikrokontroler yang akan digunakan dalam penelitian ini adalah AT89S51 produksi Atmel Corporation. Mikrokontroler digolongkan sebagai komputer karena piranti ini memiliki CPU (Central Processing Unit), memori (RAM dan ROM), dan port I/O yang merupakan tiga bagian utama pembangun sebuah komputer (MacKenzie, 1995).

Dalam struktur organisasi memori AT89S51 dikenal dua macam memori, yaitu memori program (ROM) dan memori data (RAM), program yang bersifat tetap (fixed) disimpan pada ROM (read only memory). Jika ukuran program tidak melebihi 4 Kbyte, maka program dapat disimpan pada ROM internal (dalam mikrokontroler) tetapi jika lebih besar, maka ROM eksternal dapat dimanfaatkan hingga 64 Kbyte.

\section{METODOLOGI}

Bagan perangkat keras (hardware) untuk kartu kehadiran berpassword diperlihatkan pada Gambar 1. Sistim terdiri dari kartu ber-password, kotak detektor yang didalamnya terdapat mikrokontroler AT89S51 serta tampilan papan hadir.

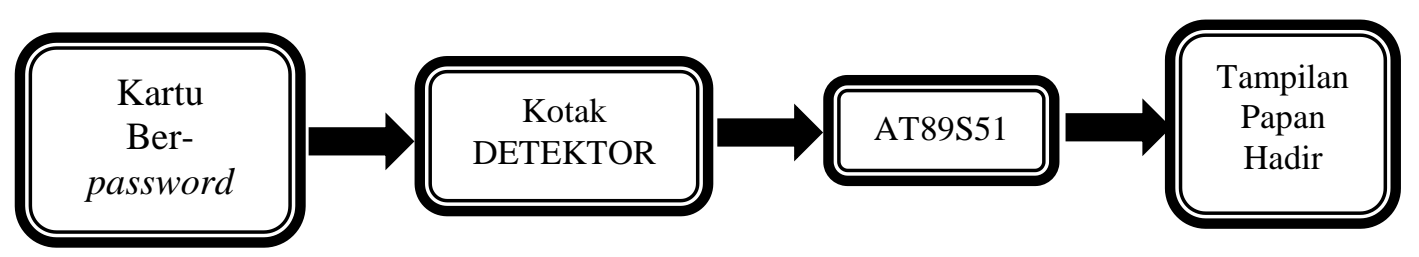

Gambar 1. Diagram blok sistem alat sistim kontrol kehadiran berbasis kartu berpassword 
Perancangan perangkat lunak (software) untuk menjalankan sistem instrumentasi berbasis mikrokontroler ditulis dalam bahasa pemograman BASCOM -8051, dengan diagram alir terdapat pada Gambar 2.

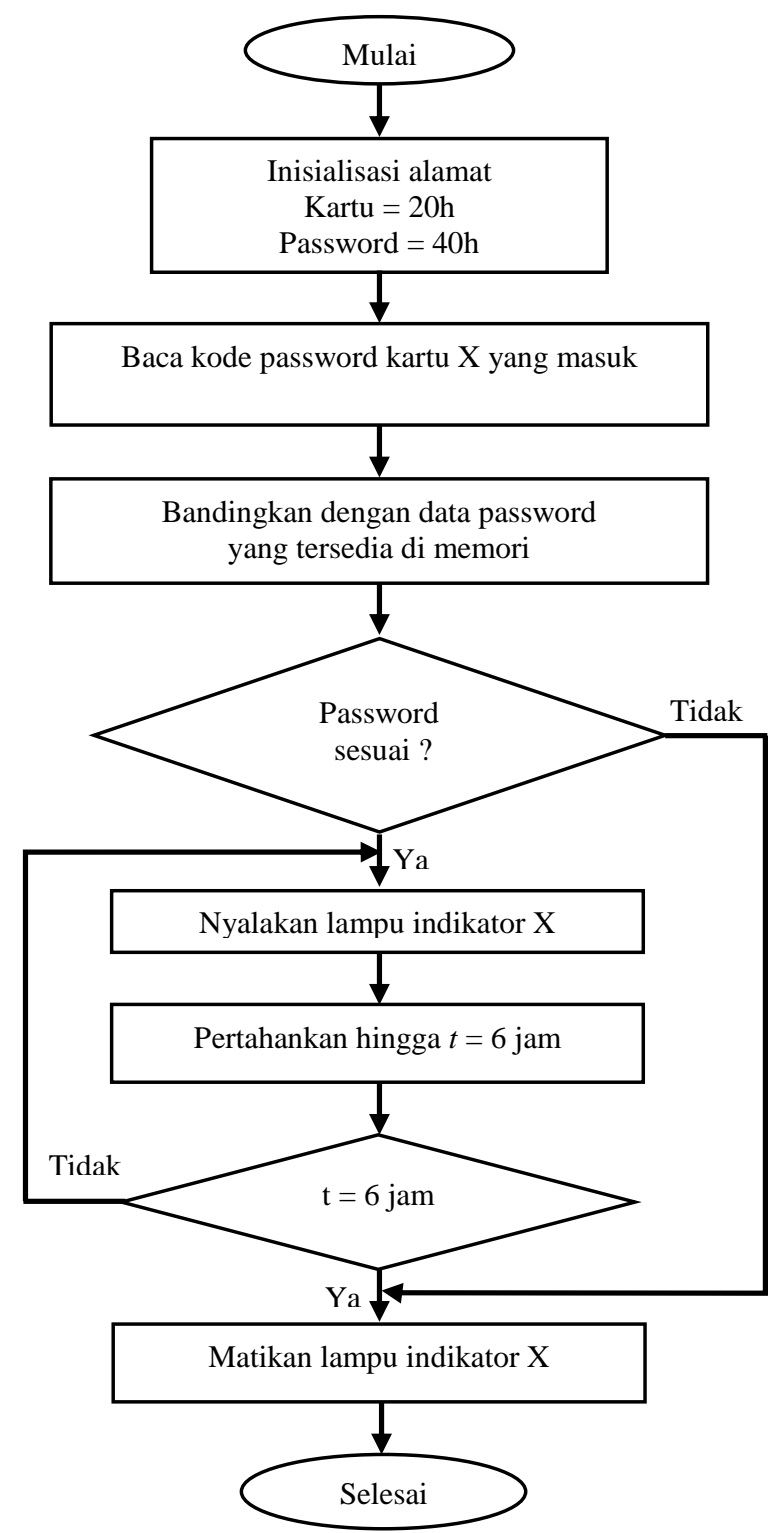

Gambar 2. Diagram alir program sistem kontrol kehadiran berbasis kartu ber-password

\section{HASIL DAN PEMBAHASAN}

Tampilan perangkat keras sistem kontrol kehadiran berbasis mikrokontroler AT89S51 menggunakan kartu ber-password dan sensor fotodioda dapat dilihat pada Gambar 3. 
ISSN 1979-4657

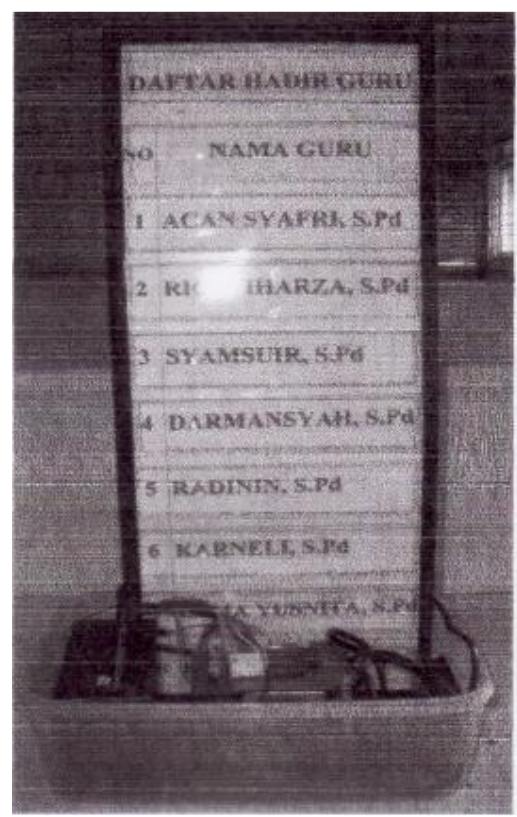

Gambar 3. Tampilan sistem kontrol kehadiran

Dengan memasukkan kartu ber-password kedalam kotak detektor maka sinyal masukan diterima fotodioda dari LED diteruskan ke mikrokontroler, kemudian mikrokontroler membandingkan dengan data yang ada di memori. Sebagai hasil tampilan yaitu papan hadir. Lampu pada papan hadir menyala bila kode password-nya cocok dengan data yang ada di memori.

Rangkaian catudaya berfungsi sebagai sumber arus DC untuk menjalankan rangkaian sensor yang membutuhkan tegangan 5 volt. Tegangan rangkaian catudaya yang dihasilkan adalah 4,9 volt. Tegangan ini dimanfaatkan oleh rangkaian mikrokontroler dan rangkaian sensor.

Kotak detektor sebagai sensor terdiri dari 8 buah LED berfungsi sebagai pemancar cahaya dan 8 buah fotodioda sebagai penerima cahaya atau sebagai sensor kemudian menggunakan resistor $330 \mathrm{ohm}$.

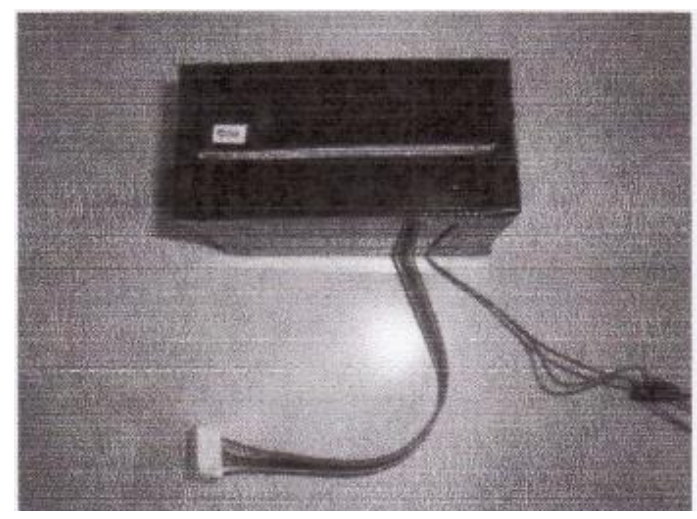

Gambar 4. Kotak detektor pembaca kartu ber-password

Hasil karakterisasi sensor fotodioda dengan berbagai variasi jarak dapat dilihat pada Gambar 5. Tegangan keluaran dari sensor fotodioda untuk jarak $0 \mathrm{~cm}$ adalah 4,92 volt 
dan untuk jarak $5 \mathrm{~cm}$ adalah 4,8 volt pengukuran ini dilakukan saat cahaya LED tidak terhalang kartu. Semakin jauh jarak, tegangan yang dihasilkan oleh fotodioda semakin kecil, maka alat yang dibuat mendekati tegangan sumber 4,8 voltpada jarak $0,5 \mathrm{~cm}$ serta disesuaikan dengan ukuran atau ketebalan kartu. Saat cahaya terhalang kartu tegangan yang dihasilkan oleh fotodioda adalah nol karena tidak ada sinyal masukan diterima oleh fotodioda.

Jarak antara LED (pemancar) dengan sensor fotodioda (penerima) digunakan \pm $0,5 \mathrm{~cm}$ pada jarak ini dihasilkan tegangan cukup baik dan juga jarak terdekat dibuat untuk bisa masuk dan keluarnya kartu berukuran $2 \mathrm{~mm}$ dan bisa menopang kartu pada kotak detektor sehingga sinyal masukan diterima fotodioda dari LED dapat tepat diterima.

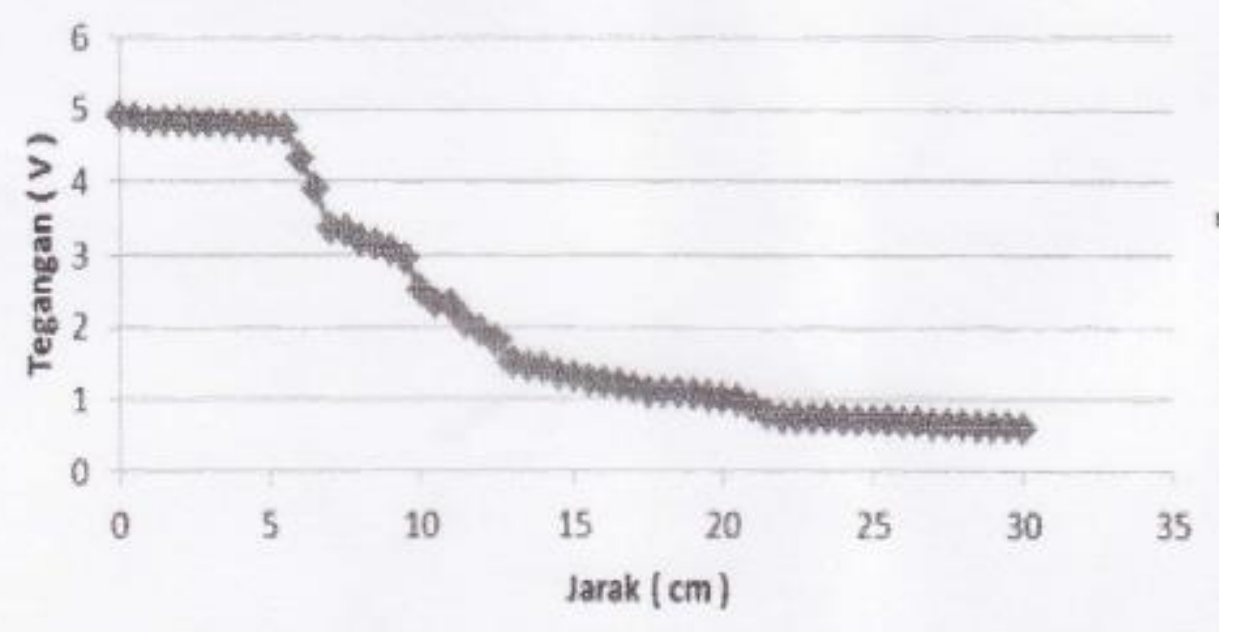

Gambar 5. Grafik hasil karakterisasi hubungan jarak LED dengan tegangan fotodioda

Kartu ber-password terbuat dari akrilik dengan ketebalan kartu $2 \mathrm{~mm}$ panjang $5 \mathrm{~cm}$ dan lebar $2,5 \mathrm{~cm}$, diameter lubang kartu adalah $\pm 0,5 \mathrm{~cm}$ atau $5 \mathrm{~mm}$, diameter lubang ini disesuaikan dengan ukuran LED yang digunakan.

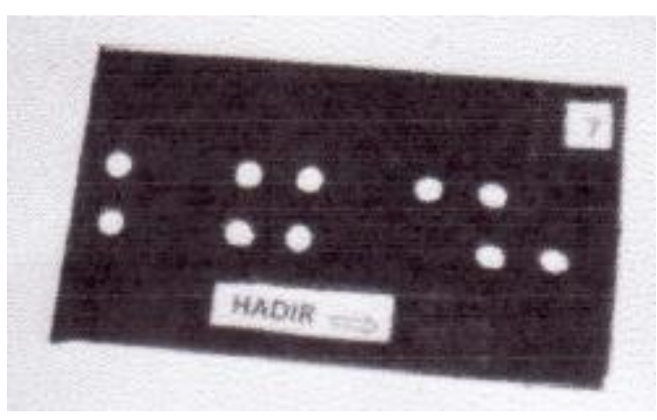

Gambar 6. Kartu ber-password

Satu kartu dibuat untuk dua buah kode password yaitu password hadir dan password pulang. Password hadir pada bagian bawah dan password pulang pada bagian atas. Untuk menggunakan password pulang dengan membalikkan kartu hadir. Gambar kartu terdapat pada Gambar 6.

Jarak dari password hadir ke pinggir bagian bawah kartu $1,8 \mathrm{~cm}$ dan jarak dari passwordpulang ke pinggir atas juga $1,8 \mathrm{~cm}$ untuk jarak antara lubang password pulang dengan lubang password hadir 0,5 cm. Setiap karti diberi kode hadir dan kode pulang sebagai penanda dan inisial nomor atau nama. 
Tegangan yang diterima fotodioda dalam ruangan tertutup (tanpa cahaya) bernilai 0,08 volt, sangat kecil sekali karena tidak ada sinyal yang diterima fotodioda. Sedangkan nilai tegangan diterima fotodioda dalam ruangan yang memiliki cahaya lampu listrik 2,1 volt dan bila lampu listrik dimatikan tegangan fotodioda 1,2 volt, nilai ini masih dipengaruhi oleh cahaya dari luar yaitu cahaya matahari yang memasuki ruangan. Sehingga dibuat kotak detektor untuk menghindari pengaruh tegangan luar.

\section{KESIMPULAN}

Berdasarkan hasil penelitian ini, maka diambil beberapa kesimpulan yaitu:

1. Lubang pada kartu dengan posisi yang berbeda dapat dijadikan pembacaan password yang dikontrol oleh mikrokontroler AT89S51 untuk mempresentasikan kehadiran.

2. Jarak LED yang terlalu jauh membuat pembacaan sensor cahaya tidak optimal. Jarak LED dan fotodioda pada kotak detektor yang dibuat adalah $0,5 \mathrm{~cm}$ dengan tegangan yang dihasilkan oleh fotodioda 4,8 volt.

\section{DAFTAR PUSTAKA}

1. Bhaskara, 2009, Rancang Bangun Sistem Pembuka Menggunakan Sensor Infrared Dan Password Berbasis Mikrokontroler. Tugas Akhir. Fakultas Teknik Telekomunikasi. Politeknik Elektronika Negeri Surabaya.

2. Fadli A., 2012, Pembuatan Catudaya, Makalah, Universitas Gunadarma, Jakarta.

3. Fraden, J, 1996, Handbook Of Modern Sensors. California : Thermoscan,Inc

4. Mackenzie, S.I (1995). The 8051 Microcontroller AT89S52. Gava Media, Yogyakarta.

5. Riki, 2007, Sistem Kontrol Motor DC Berbasis Mikrokontroler AT89S51 Menggunakan Sensor Fotodioda dan Kartu Ber-Password, Skripsi, FMIPA, Universitas Andalas, Padang.

6. Silitonga, 2010, Kunci Otomatis Sederhana Menggunakan Kartu Berlubang Berbasiskan Mikrokontroler ATMEGA8535, Skripsi, Fakultas Ilmu Komputer Dan Teknologi Informasi, Universitas Gunadarma, Jakarta 